\title{
Digoxin is Associated with Increased Mortality in Patients with Atrial Fibrillation without Concomitant Heart Failure
}

\author{
Maciej Tysarowski, MD $^{1}$; Rafael Nigri, MD $^{1}$; Brijesh Patel, MD $^{2}$; Giselle A. Suero-Abreu, $\mathrm{MD}, \mathrm{PhD}^{1}$; Balaji
} Pratap, MD ${ }^{3}$; Joseph Bastawrose, MD ${ }^{4}$; Joshua Aziz ${ }^{5}$; Hoeun Kim ${ }^{6}$; Eyal Herzog, MD ${ }^{7}$, MD and Emad F. Aziz, DO ${ }^{2}$

${ }^{1}$ Deparemtnt of Medicine, Rutgers University New Jersey Medical School, Newark, New Jersey, USA

${ }^{2}$ Division of Cardiology, Department of Medicine, Rutgers University New Jersey Medical School, Newark, New Jersey, USA

${ }^{2}$ Division of Cardiology, Department of Medicine, Cardiovascular Intensive Care Unit and Echocardiography Laboratory, Icahn School of Medicine at Mount Sinai, Mount Sinai Heart at Mount Sinai St. Luke's-Mount Sinai West Hospital, New York, USA

${ }^{3}$ Division of Cardiology, Department of Medicine, Cardiovascular Intensive Care Unit and Echocardiography Laboratory, Icahn School of Medicine at Mount Sinai, Mount Sinai Heart at Mount Sinai St. Luke's-Mount Sinai West Hospital, New York, USA

${ }^{4}$ Division of Cardiology, Mount Sinai St. Luke's and Mount Sinai West Hospitals, New York, New York, USA

${ }^{5}$ New Jersey Institute of Technology, Newark, New Jersey, USA

${ }^{6}$ University Hospital, Newark, New Jersey, USA

${ }^{7}$ Department of Cardiology, Hadassah Hebrew University Medical Center, Jerusalem, Israel

\section{Abstract}

Introduction: Atrial fibrillation $(\mathrm{AF})$ is the most common arrhythmia encountered in clinical practice and is a significant risk factor for ischemic stroke and death. Digitalis has been used for more than 200 years to treat heart conditions, including AF, and its use remains controversial due to uncertain long-term morbidity and mortality.

Methods: We conducted a cohort study of hospitalized patients with AF assessing the effects of digoxin on longterm all-cause mortality. Patients were divided into two groups: with and without heart failure (HF). We performed multivariable Cox regression analysis to assess hazard ratios (HR) for all-cause mortality depending on digoxin treatment and used propensity score matching to adjust for differences in background characteristics between treatment groups.

Results: Among 2179 consecutive patients hospitalized with AF, the median age was $73 \pm 14$, and $52.5 \%$ of patients were male, $49 \%$ had HF, and $18.8 \%$ were discharged on digoxin. Median left ventricular ejection fraction in the whole cohort was 60 (IQR 40-65). Among patients with HF, 34.5\% had preserved, 17.3\% had mid-range and 48.1\% had reduced left ventricular ejection fraction. The mean follow-up time was $3 \pm 2.05$ years. In patients without HF there was a statistically significant increased mortality in the digoxin subgroup after propensity score matching (HR $=2.23,95 \%$ CI 1.42-3.51, $\mathrm{p}<0.001)$. In contrast, in patients with HF, there was no difference in mortality between the treatment groups $(\mathrm{p}=0.92)$.

Conclusions: Digoxin use in our study was associated with increased mortality in patients with AF and without concomitant HF.

Keywords: Arrhythmia; Atrial fibrillation; Digoxin; Heart failure; Mortality; Radiofrequency ablation 
medRxiv preprint doi: https://doi.org/10.1101/2020.08.07.20169888; this version posted August 11, 2020. The copyright holder for this preprint (which was not certified by peer review) is the author/funder, who has granted medRxiv a license to display the preprint in perpetuity.

It is made available under a CC-BY-NC-ND 4.0 International license .

Tysarowski M. et al, Aug 07, 2020 - preprint version - www.medrxiv.org

\section{$\underline{\text { Introduction }}$}

Atrial fibrillation (AF) is the most common arrhythmia encountered in clinical practice, and its prevalence increases with age. It is a significant risk factor for thromboembolic stroke and affects up to $9 \%$ of the population by the age of 80 years. ${ }^{1,2}$ Moreover, a stroke in patients with $\mathrm{AF}$ is associated with higher mortality, morbidity, and longer hospital stays than those without $\mathrm{AF}^{3-5}$

Two pharmacologic treatment strategies exist for AF: rate and rhythm control. The AFFIRM trial compared the overall survival benefit of treating AF with rate or rhythm control strategies. The study demonstrated no mortality difference between rhythm control with antiarrhythmics and rate control with digoxin and AV nodal blockers. ${ }^{6,7}$ Rate control with digoxin, beta-blockers, and calcium channel blockers is now a more utilized approach for AF treatment.

Amongst the rate control drugs, digoxin is the most controversial. $^{8,9}$. It is recommended for rate control in $\mathrm{AF}$, by both the European Society of Cardiology and the American College of Cardiology/American Heart Association (ACC/AHA), as a second-line medication in patients with heart failure (HF) and third line in patients without HF. ${ }^{10}$ It has also been shown to decrease hospitalizations in patients with HF. ${ }^{11}$
Table 1 Variables included in propensity score model

\begin{tabular}{l}
\hline List of variables \\
\hline \hline Characteristics \\
Age \\
Sex \\
BMI \\
Hemoglobin level \\
\hline Risk factors \\
Length of Stay \\
Hypertension \\
Hyperlipidemia \\
Prior PCI \\
Known CAD \\
Number of risk factors \\
\hline Medications \\
Statin \\
Insulin \\
\hline \hline
\end{tabular}

Abbreviations: $B M I=$ body mass index, $C A D=$ coronary artery disease, $P C I=$ percutaneous coronary intervention.

There is conflicting data regarding digoxin effect on all-cause mortality in patients with AF with and without concomitant HF. Some studies emphasize an association between higher all-cause mortality and digoxin use in patients with and without $\mathrm{HF}^{9}$, while others deny that correlation. ${ }^{12}$ Moreover, the follow-up in most of these studies was short, consisting of 1 year.

Our study aims to assess the effect of digoxin treatment on long term all-cause mortality in patients with AF.

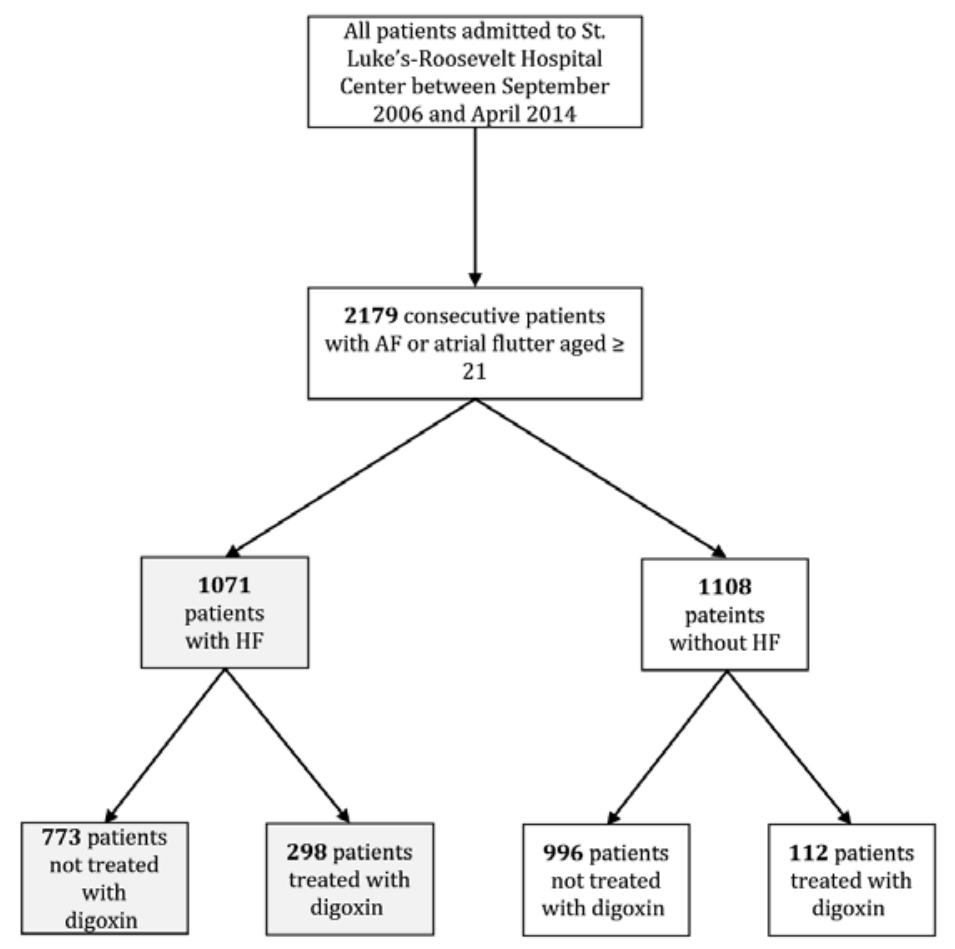

FIGURE 1 Study flow chart. Abbreviations: $\mathrm{AF}=$ atrial fibrillation, $\mathrm{HF}=$ heart failure outcome 


\section{Methods}

\subsection{Study population and data acquisition}

The study cohort is derived from the ACAP-RACE AF13 database that was established at St. Luke's-Roosevelt Hospital Center in 2004 to follow all patients admitted with AF. It included all 2179 consecutive patients admitted to the institution with the diagnosis of AF or atrial flutter between September 2006 and April 2014. The comprehensive registry included all patients' laboratory and imaging findings, and admission and discharge medications. Management of all patients was guided by utilizing the RACE pathway (R: rate control, A: anticoagulation, C: Cardioversion and E: electrophysiology) that was initially published in 2005 and updated in 2017. ${ }^{14,15}$ The pathway was implemented in the institution in 2005 and according to the pathway all patients were treated with either rate or rhythm control. Rhythm control with catheter ablation was offered to patients who met the inclusion criteria at that time to undergo the procedure. Mortality was confirmed by review of medical records, death certificates or the social security death index. Patients or relatives were interviewed at least twice during the follow-up period (physician-directed, scripted telephone interview). HF group was defined as having previously diagnosed HF (including HF with preserved EF), diagnosed with HF during hospitalization or having LVEF $\leq 35 \%$ on echocardiography during hospitalization.

\subsection{Statistical methods}

We divided all patients with AF into two groups, those with HF and those without HF and further into subgroups according to digoxin therapy (Figure 1). After verifying proportional hazard assumptions, we calculated hazard ratios (HR) for all-cause mortality in patients treated and not treated with digoxin, using Cox regression analysis. In addition, we used propensity score matching to balance the groups of patients treated, and not treated with digoxin. We used the nearest neighbor matching method with matching ratio of 1:2. Variables

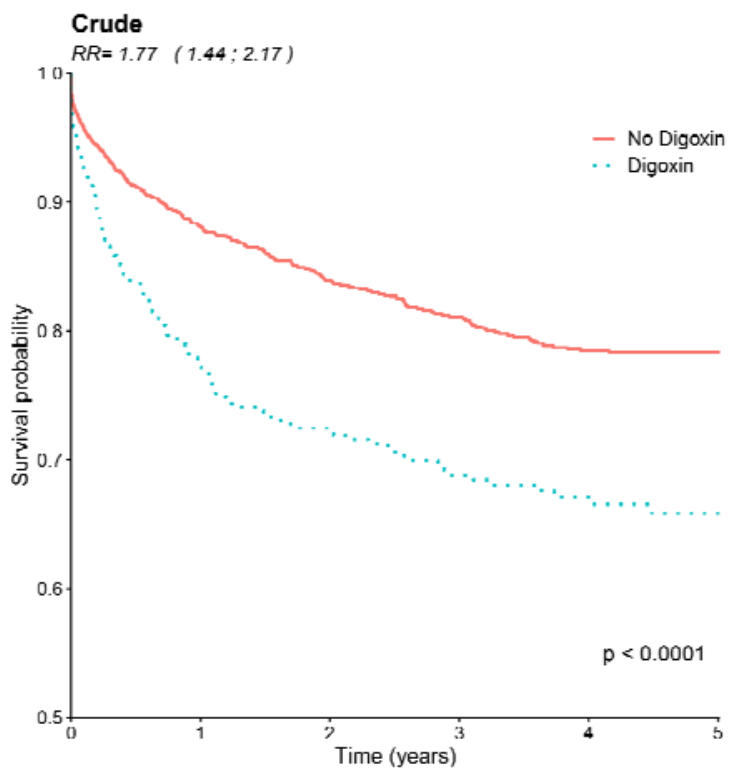

included in propensity score model are presented in Table 1.

Data are presented as mean \pm standard deviation for normally distributed continuous variables or median (25th and 75 th percentiles) for non-normal continuous variables. Shapiro-Wilk test was used to check normality of all continuous variables. Categorical variables are presented as a number (percentage). All statistical tests were 2-sided and significance was established as $\alpha=0.05$. $R$ version 3.6.1 (R Foundation for Statistical Computing, Vienna, Austria) was used for all statistical analyses.

\section{$\underline{2.3 \text { Ethics }}$}

The study met the requirements of the Declaration of Helsinki. All patients provided written follow up consent. The study protocol was accepted by Mount Sinai St. Luke's-Mount Sinai West Hospital's Institutional Review Board and individual consent for participation in anonymous data analysis was waived.

\section{Results}

Unadjusted (before propensity score matching) patient characteristics are presented in Table 2. All patients had AF and/or atrial flutter. The average age was $73 \pm 14$, and $52.5 \%$ of patients were men. There was a high prevalence of hypertension - 77\%, hyperlipidemia - $42.3 \%$, and diabetes $27.1 \%$. HF was present in $49 \%$ of all patients, and $18.8 \%$ of all patients were discharged on digoxin. Median left ventricular ejection fraction in the whole cohort was 60 (IQR 40-65). Among patients with HF, 34.5\% had preserved, $17.3 \%$ had mid-range and $48.1 \%$ had reduced left ventricular ejection fraction. Less than $5 \%$ of patients discharged without digoxin were taking it before the hospitalization, and for most patients discharged on digoxin, it was a new medication. The median

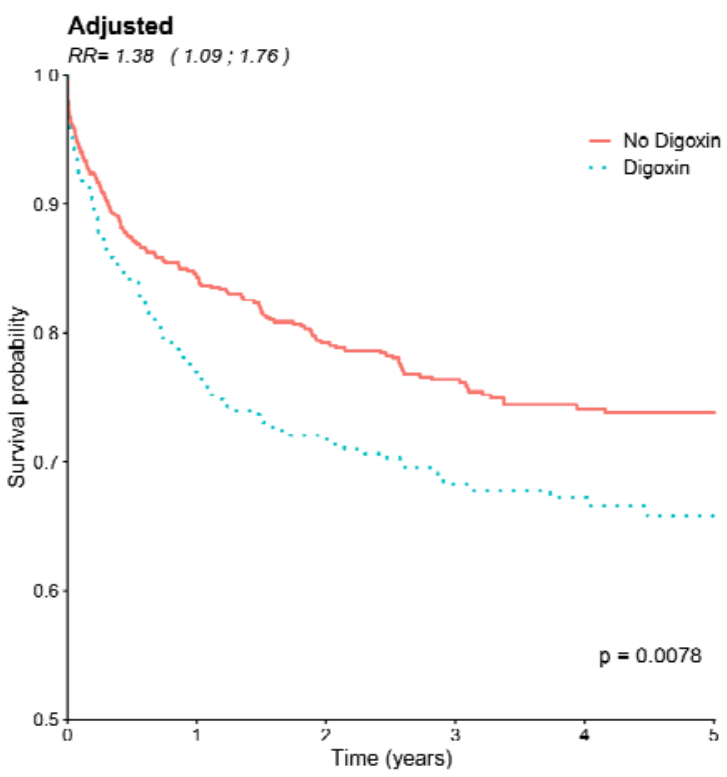

Figure 2 Survival probability for all patients. Blue line represents patients taking digoxin and red line those that did not use digoxin. The left figure shows non-adjusted survival, and the right shows survival after adjusting for propensity score. $R R$ relative risk ( $95 \%$ confidence interval) 
Tysarowski M. et al, Aug 07, 2020 - preprint version - www.medrxiv.org

LVEF of our study population was $60 \%$ and was significantly lower in the HF group. The mean follow-up time in our study was $3 \pm 2.05$ years.

Overall survival of all patients is shown in Figure 2. After adjustment (propensity score matching), there was a statistically significant increased mortality in patients treated with digoxin when compared to the non-digoxin subgroup (HR for death 1.38, 95\% CI 1.09-1.76, $\mathrm{p}=0.0078$ ). Heart failure patient survival is shown in Figure 3. After adjustment, there was no statistically significant difference in mortality between the two groups (HR for death 1.01, 95\% CI 0.761.35, $\mathrm{p}=0.92$ ).Survival curves for patients without HF are shown in Figure 4. According to our analysis, there was a statistically significant increase in mortality with digoxin use (HR of death 2.93, 95\% CI 2.74 - 3.12). This increase in mortality was maintained after adjustment with a HR of death of 2.23 (95\% CI 1.42-3.51, $\mathrm{p}<0.001)$ with digoxin use in this group.

Radiofrequency ablation rate in the whole group was $11.1 \%$ (Table 2) and was four-fold higher $14.8 \%$ in patients not treated with digoxin than the digoxin treated group 3.6\%, $(\mathrm{p}=0.002)$. There was no statistically significant difference in RFA rates among patients with HF.

\section{Discussion}

Our results suggest that while the use of digoxin was not associated with all-cause mortality in patients with $\mathrm{AF}$ and $\mathrm{HF}$, it was associated with significantly increased mortality in the group of patients with $\mathrm{AF}$ and without HF. These results are consistent with some but not all previous studies

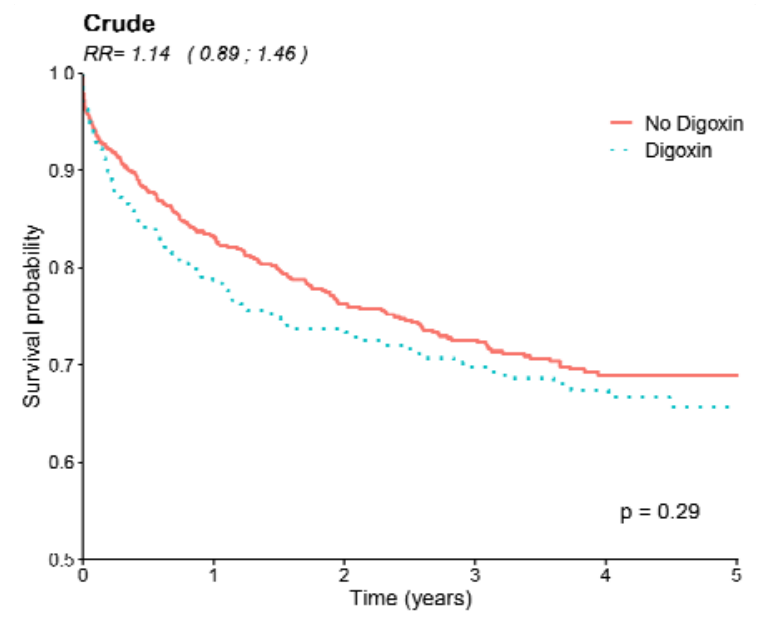

evaluating this relationship.

\subsection{Patients not stratified in HF and non-HF groups}

In a metanalysis from 2019, Vamos et al. analyzed 37 trials evaluating the effect of digoxin on patients with $\mathrm{AF}$ or $\mathrm{HF}$ as the inclusion criterium. ${ }^{16}$ In the AF subgroup of 627,620 patients, which also included patients with HF, treatment with digoxin was associated with increased mortality after adjustment $(\mathrm{HR}=1.23)$. In comparison, our study revealed a similar adjusted HR of 1.38 for all AF patients in our cohort. The mentioned metanalysis did not stratify patients into HF and non-HF subgroups.

Two recent post hoc analyses of the AFFIRM trial have been at odds regarding the mortality associated with Digoxin., ${ }^{9,17}$ The propensity-adjusted analysis by Whitbeck et al. of the AFFIRM trial has found that the use of Digoxin is associated with increased mortality in AF with or without HF. These results confirmed the findings of an earlier post hoc analysis of the AFFIRM trial in which Digoxin was also associated with higher all-cause mortality. However, Gheorghiade et al. conducted a post hoc analysis of the AFFIRM trial and found no difference in mortality associated with Digoxin use in AF after propensity matching. In the latter analysis in order to eliminate intention bias digoxin was not considered as a timedependent treatment variable and 1352 patients were excluded. These excluded patients had higher unadjusted mortality than those included in the analysis. While the findings were consistent with the AFFIRM trial results, the exclusion of a large cohort of patients with a high mortality limits the external validity of the study.

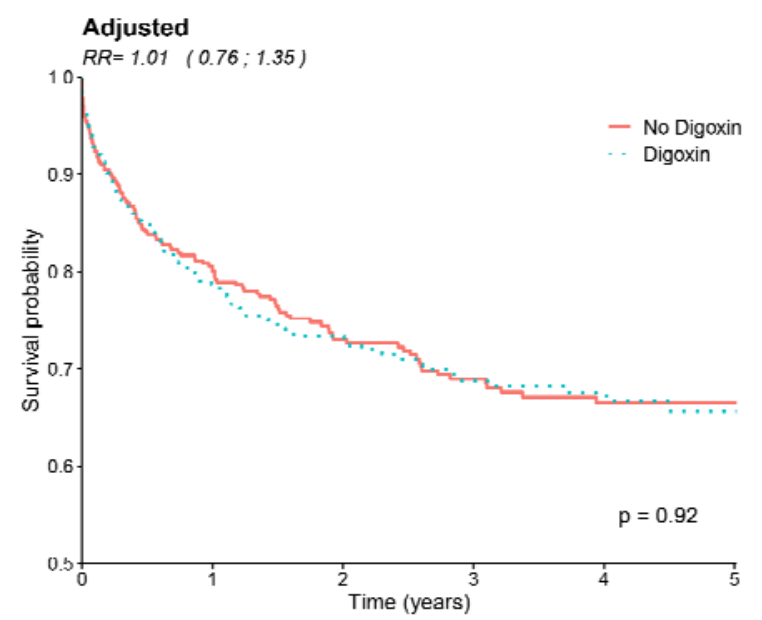

FIGURE 3 Survival probability for patients with HF. Blue line represents patients treated with digoxin and red line patients that did not use digoxin. The left figure shows non-adjusted survival, and the right shows survival adjusted for propensity score. RR relative risk (95\% confidence interval) 


\subsection{Patients without $H F$}

A 2015 metanalysis of 12 studies that used digoxin primarily for rate control of $\mathrm{AF}$ concluded that digoxin is associated with increased all-cause mortality in patients without $\mathrm{HF}$ with HR of $1.38\left(95 \%\right.$ CI, 1.12-1.71). ${ }^{18}$ ATRIA-CVRN is a cohort study consisting of over twenty-three thousand patients with newly diagnosed AF with no history of HF. It demonstrated a significant increase in mortality with digoxin (HR 1.71; 95\% CI, 1.52-1.71). ${ }^{19}$ An analysis using the RIKS-HIA database with over 4000 patients discharged from the Coronary Unit in Sweden compared outcomes of patients with AF, HF, or both. Digoxin was demonstrated again to have an increased 1-year overall mortality in patients without $\mathrm{HF}(\mathrm{HR}=1.42$; 95\% CI, 1.17-1.53) ${ }^{20}$ These three studies had similar results, but with a lower hazard ratio when compared to our analysis $(\mathrm{HR}=2.23)$. One of the main differences between the RIKS-HIA analysis and our study is the fact that our study included all patients admitted to the hospital, not only those admitted in the coronary care unit (CCU).

\subsection{Patients with $H F$}

In the mentioned metanalysis by Chamaria et al., researchers concluded that in patients with $\mathrm{AF}$ and $\mathrm{HF}$, digoxin was not associated with increased mortality (HR 1.08, 95\% CI 0.99 1.18). ${ }^{18}$ In another subgroup of patients from the RIKS-HIA database that comprised of patients with both $\mathrm{AF}$ and $\mathrm{CHF}$, there was no statistically significant difference in mortality between patients who were discharged with or without Digoxin (RR 1.00, 95\% CI, 0.94-1.06). ${ }^{20}$ Analysis of our cohort concurs with these two reports, no statistical difference in mortality was found between the patients with HF treated with or without digoxin. In patients with $\mathrm{HF}$ in addition to $\mathrm{AF}$,

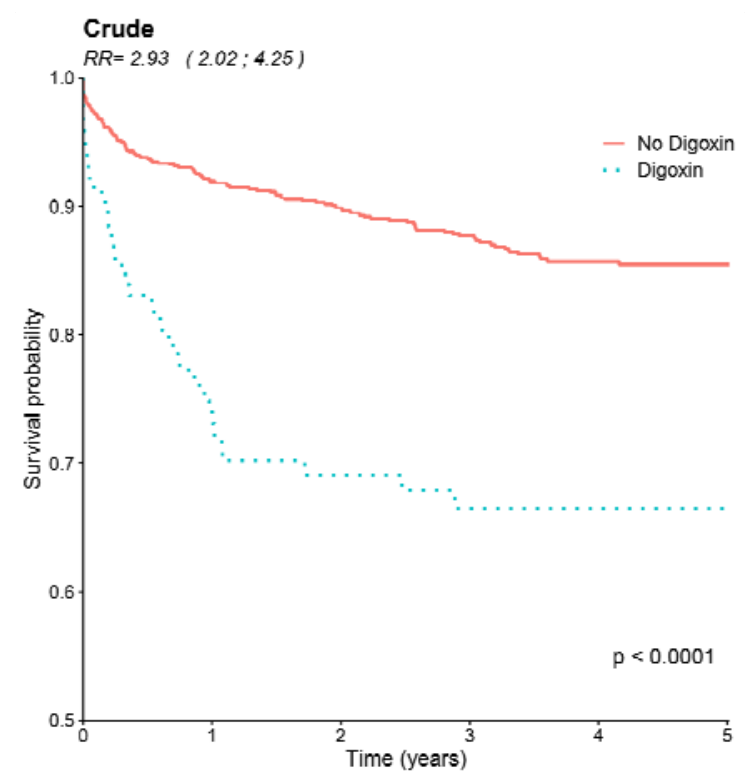

digoxin could also be of benefit due to its neurohormonal action and effect in decreasing chronotropy while increasing inotropy. ${ }^{21}$

In patients with $\mathrm{AF}$ and HF the Serum Drug Concentration (SDC) has directly affected the efficacy and associated mortality of the drug. ${ }^{22,23}$ The DIG trial is the only randomized clinical trial that assessed the mortality and morbidity of Digoxin in patients with HF. The study revealed no difference in mortality and a decrease in hospital admission with digoxin use.11 Our results are in agreement with these findings; we found no difference in mortality but a statistically longer time to readmission in the digoxin subgroup. Other studies, including a post hoc analysis of the DIG trial, demonstrated increased mortality with a SDC is greater than $1 \mathrm{ng} / \mathrm{ml}$ and a trend towards decreased mortality when the SDC is between 0.5 and $0.9 \mathrm{ng} / \mathrm{ml}^{22,23}$ Although this appears to be a discrepancy between the DIG trial and the post hoc analysis, DIG trial reported that the average SDC at one month in the Digoxin arm was less than $0.9 \mathrm{ng} / \mathrm{ml}$. A SDC of less than 1 $\mathrm{ng} / \mathrm{ml}$ has also been shown to have beneficial hemodynamic, neurohormonal, and clinical effects. ${ }^{24,25}$ These findings are also corroborated by a post hoc analysis of the ARISTOTLE trial. A Digoxin level equal or above $1.2 \mathrm{ng} / \mathrm{ml}$ was independently associated with an increased risk of death and sudden death in patients with AF with or without $\mathrm{HF}^{26}$ Recent analysis of the AF-CHF trial contradicts the conclusion

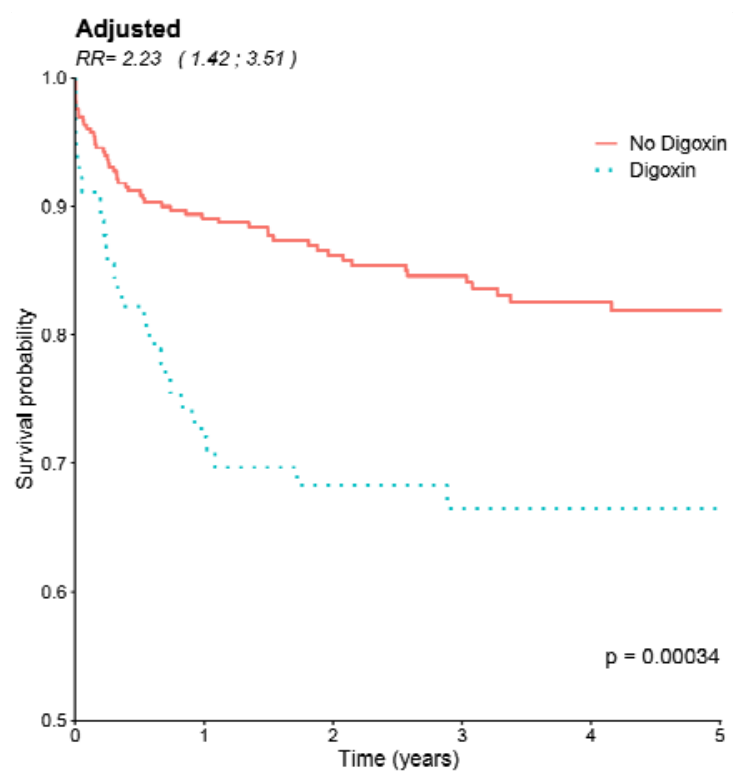

FIGURE 4 Survival probability for patients without HF. Blue line represents patients treated with digoxin and red line patients that did not use 
Table 2 Unadjusted characteristics of study participants

\begin{tabular}{|c|c|c|c|c|c|c|c|}
\hline & \multirow{2}{*}{$\begin{array}{l}\text { All patients } \\
(n=2179)\end{array}$} & \multicolumn{3}{|c|}{ Heart Failure $(n=1071)$} & \multicolumn{3}{|c|}{ No Heart Failure $(n=1108)$} \\
\hline & & $\begin{array}{l}\text { Without digoxin } \\
(\mathrm{n}=773)\end{array}$ & $\begin{array}{l}\text { With digoxin } \\
(\mathrm{n}=298)\end{array}$ & $\mathrm{p}$-value & $\begin{array}{l}\text { Without digoxin } \\
(\mathrm{n}=996)\end{array}$ & $\begin{array}{l}\text { With Digoxin } \\
(\mathrm{n}=112)\end{array}$ & p-value \\
\hline \multicolumn{8}{|l|}{ Demographics } \\
\hline Age, years & $71.31(14.35)$ & $72.31(13.78)$ & $71.85(12.70)$ & 0.615 & $69.90(15.17)$ & $75.42(13.51)$ & $<0.001$ \\
\hline Male sex, n (\%) & $1144(52.5)$ & $420(54.3)$ & $171(57.4)$ & 0.406 & $502(50.4)$ & $51(45.5)$ & 0.381 \\
\hline$B M I, \mathrm{~kg} / \mathrm{m}^{2}$ & $26.8(23.1-32.2)$ & $26.8(23.0-32.2)$ & $27.0(23.4-32.6)$ & 0.608 & $27.0(23.4-32.3)$ & $25.4(21.3-30.2)$ & 0.015 \\
\hline GFR Cockcroft-Gault, mL/min & $79.33(61.42)$ & $69.81(49.34)$ & $75.24(77.33)$ & 0.186 & $87.33(50.95)$ & $87.90(124.93)$ & 0.929 \\
\hline LVEF (\%) & $60(40-65)$ & $40(20-60)$ & $35(20-60)$ & 0.004 & $60(60-65)$ & $60(60-65)$ & 0.367 \\
\hline \multicolumn{8}{|l|}{ Comorbidities, n (\%) } \\
\hline Hypertension & $1691(77.7)$ & $644(83.3)$ & 237 (79.5) & 0.173 & $727(73.3)$ & $83(74.1)$ & 0.941 \\
\hline DM & $590(27.1)$ & $255(33.0)$ & $87(29.2)$ & 0.263 & $224(22.6)$ & $24(21.4)$ & 0.875 \\
\hline CAD & $173(8.0)$ & $65(8.4)$ & $30(10.1)$ & 0.462 & $76(7.7)$ & $2(1.8)$ & 0.035 \\
\hline Hyperlipidemia & $921(42.3)$ & $351(45.4)$ & $118(39.6)$ & 0.099 & $411(41.4)$ & $41(36.6)$ & 0.377 \\
\hline Smokers & $911(41.8)$ & $349(45.1)$ & $141(47.3)$ & 0.569 & $377(37.9)$ & $44(39.3)$ & 0.846 \\
\hline \multicolumn{8}{|l|}{ Home medications, n (\%) } \\
\hline Aspirin & $1002(46.2)$ & $379(49.2)$ & $140(47.0)$ & 0.556 & $437(44.1)$ & $46(41.1)$ & 0.603 \\
\hline Clopidogrel & $189(8.7)$ & $85(11.0)$ & $20(6.7)$ & 0.044 & $76(7.7)$ & $8(7.1)$ & 0.989 \\
\hline Beta-Blockers & $1259(58.0)$ & $531(69.0)$ & $192(64.4)$ & 0.178 & $480(48.5)$ & $56(50.0)$ & 0.838 \\
\hline Digoxin & $234(10.8)$ & $33(4.3)$ & $135(45.3)$ & $<0.001$ & $29(2.9)$ & $37(33.0)$ & $<0.001$ \\
\hline ACEI/ARB & $936(43.1)$ & $395(51.2)$ & $151(50.7)$ & 0.923 & $349(35.3)$ & $41(36.6)$ & 0.857 \\
\hline ССВ & $707(32.6)$ & $250(32.4)$ & $79(26.5)$ & 0.071 & $334(33.8)$ & $44(39.3)$ & 0.289 \\
\hline Diuretics & $818(37.7)$ & $428(55.5)$ & $160(53.7)$ & 0.640 & $206(20.8)$ & $24(21.6)$ & 0.939 \\
\hline Spironolactone & $87(4.0)$ & $42(5.4)$ & $23(7.7)$ & 0.211 & $18(1.8)$ & $4(3.6)$ & 0.369 \\
\hline Statins & $891(41.0)$ & $377(48.9)$ & $117(39.3)$ & 0.006 & $357(36.1)$ & $40(35.7)$ & 1 \\
\hline Insulin & $168(7.7)$ & $85(11.0)$ & $20(6.7)$ & 0.044 & $58(5.9)$ & $5(4.5)$ & 0.698 \\
\hline Antiarrhythmics & $194(8.9)$ & $77(10.0)$ & $28(9.4)$ & 0.882 & $81(8.1)$ & $8(7.1)$ & 0.851 \\
\hline Anticoagulation & $786(36.1)$ & $288(37.3)$ & $119(40.1)$ & 0.437 & $342(34.4)$ & $37(33.0)$ & 0.853 \\
\hline \multicolumn{8}{|l|}{ Discharge Medications, n (\%) } \\
\hline Beta blockers & $1492(68.8)$ & $590(76.5)$ & $251(84.20)$ & 0.007 & $574(58)$ & $77(68.8)$ & 0.037 \\
\hline Calcium Channel blockers & $1112(51.2)$ & $335(43.4)$ & $164(55.0)$ & 0.001 & $539(54.5)$ & $74(66.1)$ & 0.025 \\
\hline Antiplatelet Therapy & $1340(61.7)$ & $504(65.3)$ & $187(62.8)$ & 0.481 & $580(58.6)$ & $69(61.6)$ & 0.615 \\
\hline Anticoagulation & $1809(83.2)$ & $638(82.6)$ & $269(90.3)$ & 0.003 & $804(81.0)$ & $98(87.5)$ & 0.122 \\
\hline Rhythm Control Strategy & $371(17)$ & $135(17.5)$ & $63(21.1)$ & 0.193 & $153(15.4)$ & $20(17.9)$ & 0.581 \\
\hline Rate Control Strategy & $1577(72.4)$ & $563(72.8)$ & $232(77.9)$ & 0.108 & $691(69.4)$ & $91(81.2)$ & 0.012 \\
\hline Length of Stay, days & $5(3-9)$ & $6(4-10)$ & $9(5-13)$ & $<0.001$ & $4(2-7)$ & $8(4.75-16)$ & $<0.001$ \\
\hline \multirow{3}{*}{$\begin{array}{l}\text { Time to readmission, days } \\
\text { Mortality during follow-up, } n \\
\text { (\%) } \\
\text { RFA during follow-up, } \mathbf{n}(\%)\end{array}$} & $983.35(798.56)$ & $802.14(809.93)$ & $938.85(838.26)$ & 0.014 & $1119.90(752.14)$ & $1138.08(757.49)$ & 0.809 \\
\hline & $462(21.2)$ & $209(27.0)$ & $92(30.9)$ & 0.240 & $125(12.6)$ & $36(32.1)$ & $<0.001$ \\
\hline & $241(11.1)$ & $71(9.2)$ & $19(6.4)$ & 0.173 & $147(14.8)$ & $4(3.6)$ & 0.002 \\
\hline
\end{tabular}

ote: Values represent mean ( \pm standard deviation), median (IQR; 25 th -75 th percentiles), or number (\%). Bold values indicate statistical significance.

Abbreviations: $A C E I / A R B=$ angiotensin-converting enzyme inhibitor/angiotensin receptor blocker, $B M=$ body mass index, $C A D=$ coronary artery disease, $C C B=c a l c i u m$ channel blockers, DM=Diabetes Mellitus,

$H D L=$ high density lipoprotein, $I Q R=$ in terquartile range, $L D L=$ low density lipoprotein, $\mathrm{GFR}=$ glomerular filtration rate, $\mathrm{LV} E F=$ left ven tricular ejection fraction, $\mathrm{RFA}=$ radiofrequency ablation 
that digoxin is not associated with increased mortality in patients with $\mathrm{HF}$ and AF. The analysis revealed a high risk of death among all patients, but had a statistically significant higher all cause deaths, cardiac deaths and arrhythmic deaths in the Digoxin subgroup. These findings could have been influenced by the Digoxin serum level which was not measured in the study. ${ }^{27}$

\subsection{Rates of radiofrequency ablation}

In the non-HF group, the rate of radiofrequency ablation was more than four times higher in the group discharged without digoxin, a statistically significant difference. This may suggest that digoxin could potentially provide substantial AF symptom improvement secondary to better rate control and decreasing the need for invasive procedures. However, during the study duration the results of the CASTLE-AF was not yet published and there might have been procrastination in offering ablation to patients with severe heart failure. ${ }^{28}$

\section{Study limitations and strengths}

We conducted an observational and single-center study. Nonrandom assignment to digoxin treatment in study participants is reflected in differences between groups in Table 2. There are reports suggesting that prescription bias in observational digoxin studies far exceeds the true effect of the treatment, and thus, even after adjustment, they fail to capture the real consequences of the medication.29 Since digoxin would have been added as 3rd line agent in patients without HF, it can be assumed that rate control was difficult and these patients would have had higher mortality regardless of digoxin use in these patients. Our registry contained SDC levels only for a limited number of patients, mostly obtained for suspected digoxin toxicity, so we did not include them in our analysis to avoid selection bias. We also had no data on the further specification of HF into HF with preserved ejection fraction, $\mathrm{HF}$ with moderately reduced and reduced ejection fraction.

Our study included a relatively large population of 2197 consecutive diverse inner-city hospital patients. It had a follow-up period of mean of 3 years, longer than in most previous digoxin studies. We evaluated all-cause mortality, being one of the most clinically meaningful outcomes. We used propensity score matching to account for the digoxin prescription bias, and the differences in outcomes persisted, although with less effect size.

\section{Conclusions and clinical indications}

Digoxin use was associated with an increased all causemortality in patients with AF and without concomitant HF. No difference in mortality was established in patients with $\mathrm{AF}$ with HF. These results suggest the need for the careful use of digoxin, despite being recommended in both European and
ACC guidelines as a third-line agent of rate control in AF in patients without HF.

There is still controversy about whether digoxin increases mortality in patients with AF, especially in the subgroup without HF. This needs to be studied further with large randomized clinical trials.

\section{CRediT authorship contribution statement}

Maciej Tysarowski: conceptualization, methodology, investigation, validation, data curation, writing - original draft, review \& editing, visualization, project administration, formal analysis, software, resources. Rafael Nigri: conceptualization, methodology, investigation, validation, data curation, writing - original draft, review \& editing, visualization, project administration, formal analysis, software, resources. Brijesh Patel: investigation, resources, data curation, writing - review \& editing. Giselle A. SueroAbreu: investigation, resources, data curation, writing review \& editing. Balaji Pratap: investigation, resources, data curation, conceptualization, methodology. Joseph Bastawrose: investigation, resources, data curation, , methodology. Joshua Aziz: data curation, methodology. Hyoeun Kim: investigation, resources, data curation, conceptualization, methodology. Eyal Herzog: investigation, resources, data curation, conceptualization, methodology. Emad F. Aziz: conceptualization, methodology, investigation, validation, resources, data curation, writing - original draft, review \& editing, visualization, project administration.

\section{Conflict of Interest:}

The authors declare no competing financial interests.

\section{References}

1. Page RL. Clinical practice. Newly diagnosed atrial fibrillation. N Engl J Med 2004;351:2408-16.

2. Stewart S, Hart CL, Hole DJ, McMurray JJ. A populationbased study of the long-term risks associated with atrial fibrillation: 20-year follow-up of the Renfrew/Paisley study. Am J Med 2002;113:359-64.

3. Steger C, Pratter A, Martinek-Bregel M, et al. Stroke patients with atrial fibrillation have a worse prognosis than patients without: data from the Austrian Stroke registry. Eur Heart J 2004;25:1734-40.

4. Tu HT, Campbell BC, Churilov L, et al. Frequent early cardiac complications contribute to worse stroke outcome in atrial fibrillation. Cerebrovasc Dis 2011;32:454-60. 
Tysarowski M. et al, Aug 07, 2020 - preprint version - www.medrxiv.org

5. Alkhouli M, Alqahtani F, Aljohani S, Alvi M, Holmes DR. Burden of Atrial Fibrillation-Associated Ischemic Stroke in the United States. JACC Clin Electrophysiol 2018;4:618-25.

6. Zimetbaum P. Is rate control or rhythm control preferable in patients with atrial fibrillation? An argument for maintenance of sinus rhythm in patients with atrial fibrillation. Circulation 2005;111:3150-6; discussion 6-7.

7. Wyse DG, Waldo AL, DiMarco JP, et al. A comparison of rate control and rhythm control in patients with atrial fibrillation. $\mathrm{N}$ Engl J Med 2002;347:1825-33.

8. Charnigo R, Khairy P, Guo J, Shohoudi A, Elayi CS. Use of digoxin in atrial fibrillation: One step further in the mortality controversy from the AFFIRM study. Pacing Clin Electrophysiol 2018;41:713-9.

9. Whitbeck MG, Charnigo RJ, Khairy P, et al. Increased mortality among patients taking digoxin--analysis from the AFFIRM study. Eur Heart J 2013;34:1481-8.

10. European Heart Rhythm A, European Association for Cardio-Thoracic S, Camm AJ, et al. Guidelines for the management of atrial fibrillation: the Task Force for the Management of Atrial Fibrillation of the European Society of Cardiology (ESC). Eur Heart J 2010;31:2369-429.

11. Digitalis Investigation $\mathrm{G}$. The effect of digoxin on mortality and morbidity in patients with heart failure. N Engl J Med 1997;336:525-33

12. Mulder BA, Van Veldhuisen DJ, Crijns HJ, et al. Digoxin in patients with permanent atrial fibrillation: data from the RACE II study. Heart Rhythm 2014;11:1543-50.

13. Aziz EF, Pratap B, De Benedetti Zunino ME, et al. Success in implementing a hospital-wide evidence-based clinical pathways system for the management of cardiac patients: the ACAP program experience. Crit Pathw Cardiol 2011;10:22-8.

14. Herzog E, Fischer A, Steinberg JS. The rate control, anticoagulation therapy, and electrophysiology/antiarrhythmic medication pathway for the management of atrial fibrillation and atrial flutter. Crit Pathw Cardiol 2005;4:121-6.

15. Herzog E, Argulian E, Levy SB, Aziz EF. Pathway for the Management of Atrial Fibrillation and Atrial Flutter. Crit Pathw Cardiol 2017;16:47-52.

16. Vamos M, Erath JW, Benz AP, Lopes RD, Hohnloser SH. Meta-Analysis of Effects of Digoxin on Survival in Patients with
Atrial Fibrillation or Heart Failure: An Update. Am J Cardiol 2019;123:69-74.

17. Gheorghiade M, Fonarow GC, van Veldhuisen DJ, et al. Lack of evidence of increased mortality among patients with atrial fibrillation taking digoxin: findings from post hoc propensitymatched analysis of the AFFIRM trial. Eur Heart J 2013;34:1489-97.

18. Chamaria S, Desai AM, Reddy PC, Olshansky B, Dominic P. Digoxin Use to Control Ventricular Rate in Patients with Atrial Fibrillation and Heart Failure Is Not Associated with Increased Mortality. Cardiol Res Pract 2015;2015:314041.

19. Freeman JV, Reynolds K, Fang M, et al. Digoxin and risk of death in adults with atrial fibrillation: the ATRIA-CVRN study. Circ Arrhythm Electrophysiol 2015;8:49-58.

20. Hallberg P, Lindback J, Lindahl B, Stenestrand U, Melhus $\mathrm{H}$, group R-H. Digoxin and mortality in atrial fibrillation: a prospective cohort study. Eur J Clin Pharmacol 2007;63:959-71.

21. Vardas PE, Kanoupakis EM, Kochiadakis GE, Simantirakis EN, Marketou ME, Chlouverakis GI. Effects of long-term digoxin therapy on heart rate variability, baroreceptor sensitivity, and exercise capacity in patients with heart failure. Cardiovasc Drugs Ther 1998;12:47-55.

22. Rathore SS, Curtis JP, Wang Y, Bristow MR, Krumholz HM. Association of serum digoxin concentration and outcomes in patients with heart failure. JAMA 2003;289:871-8.

23. Ahmed A, Rich MW, Love TE, et al. Digoxin and reduction in mortality and hospitalization in heart failure: a comprehensive post hoc analysis of the DIG trial. Eur Heart J 2006;27:178-86.

24. Adams KF, Jr., Gheorghiade M, Uretsky BF, Patterson JH, Schwartz TA, Young JB. Clinical benefits of low serum digoxin concentrations in heart failure. J Am Coll Cardiol 2002;39:946-53.

25. Slatton ML, Irani WN, Hall SA, et al. Does digoxin provide additional hemodynamic and autonomic benefit at higher doses in patients with mild to moderate heart failure and normal sinus rhythm? J Am Coll Cardiol 1997;29:1206-13.

26. Lopes RD, Rordorf R, De Ferrari GM, et al. Digoxin and Mortality in Patients With Atrial Fibrillation. J Am Coll Cardiol 2018;71:1063-74.

27. Elayi CS, Shohoudi A, Moodie E, et al. Digoxin, mortality, and cardiac hospitalizations in patients with atrial fibrillation and 
medRxiv preprint doi: https://doi.org/10.1101/2020.08.07.20169888; this version posted August 11, 2020. The copyright holder for this preprint (which was not certified by peer review) is the author/funder, who has granted medRxiv a license to display the preprint in perpetuity.

It is made available under a CC-BY-NC-ND 4.0 International license.

heart failure with reduced ejection fraction and atrial fibrillation: An AF-CHF analysis. Int J Cardiol 2020;313:48-54.

28. Oral H, Pappone C, Chugh A, et al. Circumferential pulmonary-vein ablation for chronic atrial fibrillation. N Engl J Med 2006;354:934-41.

29. Aguirre Davila L, Weber K, Bavendiek U, et al. Digoxinmortality: randomized vs. observational comparison in the DIG trial. Eur Heart J 2019;40:3336-41. 